In the second calculation, the July 1973 temperature profile was used as an initial condition, and Equation $\left(I^{\prime}\right)$ was again integrated, this time simulating a time period of one year. In this model, snow was allowed to accumulate on the ice surface. The accumulation pattern of the snow cover as a function of time was determined from climatic records from nearby weather stations. The temperature variation at the snow-air interface was also determined from these records, using measured lapse rates to correct for differences in altitude (private communication from R. Barry in 1974). Calculations using this model suggest that three factors have a significant influence on the temperature distribution in the ice. One is the fact that most accumulation occurs in the fall and spring, with relatively little accumulation during the winter. The second is that thermal diffusivity of the snow apparently increases during the early spring as atmospheric temperatures begin to rise. The third and most important factor is that the snow-ice interface remains at $0^{\circ} \mathrm{C}$ late into the fall due to the presence of melt water that percolated down through the accumulating snow cover in the early fall, and the temperature of this interface rises to $0^{\circ} \mathrm{C}$ early in the spring, again due to percolation of melt water.

The temperature measurements and climatic records were also used to estimate values for $\Delta \theta$ on the Barnes Ice Cap. In the ablation area and superimposed ice zone $\Delta \theta$ is 2 to $4 \mathrm{deg}$. Then there is a rapid increase to about $5 \mathrm{deg}$ in the lower part of the soaked zone. This jump occurs over a distance of only a couple of kilometers across the boundary between the two zones.

Perhaps the most significant consequence of this increase in surface temperature in the superimposed ice and soaked zones is that the temperature throughout this part of a glacier will also increase by approximately the same amount. Thus if the base of a glacier were not already at the pressure melting temperature up-glacier from the soaked zone, it is likely that it would rise to the pressure melting temperature somewhere beneath the soaked or superimposed ice zones. The consequences of this for basal erosion and the entrainment of morainal material need to be examined.

REFERENCE

Carslaw, H. S., and Jaeger, J. C. 1959. Conduction of heat in solids. Second edition. Oxford, Clarendon Press.

\title{
A MOVIE FILM ILLUSTRATING THE NUMERIGAL MODELLING OF PERIODICALLY SURGING ICE MASSES
}

\author{
By W. F. Budd
}

(Antarctic Division, Department of Science, 568 St Kilda Road, Melbourne, Victoria 3004, Australia)

and $\mathrm{B} . \mathrm{J}$. MaInnes

(Meteorology Department, University of Melbourne, Parkville, Victoria 3052, Australia)

Abstract. A general two-dimensional numerical model for a typical flow line of a glacier or ice cap has been developed which results in periodical surging for certain ranges of the input parameters. The input includes the bedrock and surface-balance profiles along the flow line, some three-dimensional parameterization depending on the cross-section shape and the flow-line patterns, the flow properties of the ice, and a numerical basal lubrication factor. 
The movie shows how a number of different ice masses grow from zero thickness to either steady state or a periodically surging state depending on the input. Typical examples of real surging ice masses from the small to the large are closely matched by the model in many effects such as the period, duration, and speed of the surges, as well as the length and thickness changes.

A preliminary study for the surging potential of a flow line in east Antarctica is also made even though the full temperature modelling is not included. The results indicate that periodic surging of the ice sheet can develop in spite of the expected high viscosity. The resultant surface profile is very similar to the measured profile. For much lower viscosities steady-state, fast-sliding, ice-stream flow develops. 